NASA TM- 87164

NASA Technical Memorandum 87164

\title{
Probability of Detection of Internal Voids in Structural Ceramics Using Microfocus Radiography
}

George Y. Baaklini

Cleveland State University

Cleveland, Ohio

and

Don J. Roth

Lewis Research Center

Cleveland, Ohio

November 1985

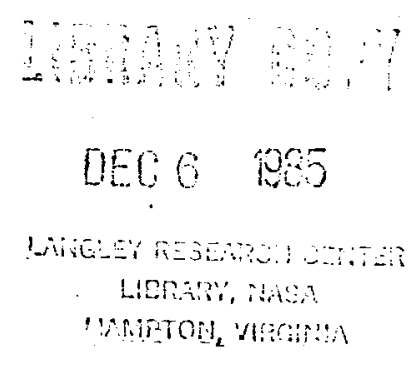




\section{PROBABILITY OF DETECTION OF INTERNAL VOIDS IN STRUCTURAL CERAMICS USING MICROFOCUS RADIOGRAPHY}

George Y. Baaklini

Cleveland State University

Cleveland, Ohio

and

Don J. Roth

National Aeronautics and Space Administration

Lewis Research Center

Cleveland, Ohio 44135

\section{SUMMARY}

The rellability of microfocus x-radiography for detecting internal voids in structural ceramic test specimens was statistically evaluated. The microfocus system was operated in the projection mode using low $x$-ray photon energies $(\leq 20 \mathrm{keV})$ and a $10 \mu \mathrm{m}$ focal spot. The statistics were developed for implanted internal voids in green and sintered silicon carbide and silicon nitride test specimens. These statistics were compared with previouslyobtained statistics for implanted surface voids in similar specimens. Problems associated with void implantation and characterization are discussed. Statistical results are given as probability-of-detection curves at a 95 percent confidence level for voids ranging in size from 20 to $528 \mu \mathrm{m}$ in diameter.

\section{INTRODUCTION}

Monolithic structural ceramics are under investigation as candidate materials for hot-section components in advanced turbine engines (refs. 1 and 2). Before universal use of these materials is justified, methods for assessing and assuring their reliability need to be developed (refs. 3 to 7). Reliability of structural ceramics such as silicon nitride and silicon carbide requires fabrication process control to reduce the incidence of various flaws and to assure that any flaws that occur are small, few, and noncritical. Advanced non-destructive evaluation (NDE) techniques are needed to detect critical flaws and to assure that ceramic components operate rellably (refs. 6 and 8). Research is being conducted to identify and investigate appropriate NDE techniques for application to structural ceramics. When used at early stages of ceramic component fabrication NDE techniques can help identify and avoid processing methods that lead to unreliable, nonuniform, sertously flawed ceramic parts (refs. 8 to 13).

General porosity and distributions of discrete voids can cause wide strength variations and unacceptably low strength in monolithic ceramics (refs. 14 to 17). Large voids or pores in green ceramics affect their ability to reach high density upon sintering. Therefore, it is important to detect and characterize voids in structural ceramics. X-radiography (refs. 18 and 19) is particularly suitable for green ceramics because of its noncontacting and noninvasive nature. Further, X-radiography is an effective NDE technique for as-fired sintered ceramics.

Abbreviated version presented at Symposium on Defect Properties and Processing of High Technology Nonmetallic Materials sponsored by the Materials Research Society, Boston, Massachusetts, December 2-6, 1985. 
The 1 imitations of $x$-radiography for detecting and characterization of internal voids in ceramics are currently not well defined. In addition, probability-of-detection (POD) statistics for critical size voids have not been established heretofore. Some prior work has investigated conventional and microfocus $x$-radiography for evaluating structural ceramics. Kossowsky (ref. 20) and Richerson et al. (ref. 21) have reported limits of resolution for defects in hot-pressed and reaction-bonded silicon nitride. The sensitivity capabilities reported were on the order of 0.5 percent of thickness for high density inclusions and on the order of 3 percent of thickness for clusters of voids. However, previous findings have not established POD statistics relative to any criticaliy sized defects. A recent study at NASA Lewis Research Center (ref. 9) established the rellablitity of detection of surface volds in structural ceramics by conventional and microfocus $x$-radiography. It was reported that microfocus $x$-radiography substantially increased the surface void detection capability.

This paper describes statistical findings concerning the detection reliability of microfocus $x$-radiography for internal voids in green and sintered silicon carbide and silicon nitride ceramics. POD statistics were obtained by using espectally-prepared test specimens implanted with internal voids 20 to $528 \mu \mathrm{m}$ in diameter. Problems associated with void implantation and characterization (i.e., measurment) are discussed.

\section{THEORY AND ANALYTICAL PROCEDURE}

\section{Radiographic Parameters}

$X$-rays are attenuated exponentially by matter, and their transmitted intensity (ref. 22) can be expressed as

$$
I=I_{0} e^{(-\mu / \rho)(\rho x)}
$$

where $I_{0}$ is the original beam intensity, $\mu / \rho$ is the mass attenuation coefficient $\left(\mathrm{cm}^{2} / \mathrm{g}\right), \rho$ is the density $\left(\mathrm{g} / \mathrm{cm}^{3}\right)$, and $x$ is the section thickness $(\mathrm{cm})$. Radiographic detectability depends on the spatial resolution of the radiographic system and on the image contrast recorded by the radiographic detector. The spatial resolution is a function of the film (detector) graininess, which governs signal-to-noise ratio, and of the geometric resolution $R$ given by

$$
R \geq \frac{U_{g}}{M}
$$

where $M$ is the $x$-ray image magnification given by

$$
M=\frac{(b+a)}{a}
$$

where $a$ is the source-to-object distance, and $b$ is the object-to-film distance. $U_{g}$, the geometric unsharpness is given by 


$$
u_{g}=f \frac{b}{a}
$$

where $f$ is the focal spot size. It follows that $R$ can be given as

$$
R=f \frac{b}{a+b}
$$

The image contrast $C$ (ref. 22) is given by

$$
C=\frac{0.43\left(\mu_{1}-\mu_{2}\right) D G_{r}}{I+\left(I_{s} / I_{d}\right)}
$$

where $\mu_{1}$ is the attenuation coefficient of the matrix, $\mu_{2}$ is the attenuation coefficient of the defect, $D$ is the thickness of the defect in the direction of the x-ray beam, $G_{r}$ is the film gradient, $I_{s}$ is the intensity of the scattered radiation, and $I_{d}$ is the intensity of the direct image-forming radiation. As shown by equation (6), a smaller ratio $I_{s} / I_{d}$ and a larger difference $\Delta \mu=\mu_{1}-\mu_{2}$ are needed to improve the image contrast.

Radiographic detectability of defects expressed in terms of a thickness sensitivity is given by

$$
\text { Thickness sensitivity }=\frac{D}{T} 100 \text {, percent }
$$

where $D$ is the dimension of the defect in the $x$-ray beam direction and $T$ is the thickness of the matrix specimen in the same direction.

To maximize detectability, it is necessary to have (1) a high image contrast to record the differences in $x$-ray absorption between the defect and the matrix and (2) a spatial resolution smaller than the defect under evaluation yet larger than the film graininess (i.e., high spatial signal-to-noise ratio). Microfocus $x$-radiography has attributes that satisfy these requirements. A schematic of microfocus projection radiography is shown in figure 1 . In the microfocus system, $f$, the focal spot size is very small, hence, from equation (5) the geometric resolution is assured. In the projection mode the ratio $I_{s} / I_{d}$ is small and results in high image contrast, equation (6) (ref. 23). The differenece in $x$-ray absorption between the defect and the matrix increases when $x$-ray photon energy decreases (ref. 24). Therefore, using a target (anode) material which emits low photon energies substantially enhances radiographic detectability (ref. 9). Even for voids in silicon carbide and silicon nitride where differential absorption even at low energies is small, image contrast can be increased by use of the projection mode and by optimizing exposure conditions.

\section{Statistical Analysis}

Rellability assessment of microfocus $x$-radiography is probabilistic in nature due to combined uncertainties associated the equipment, operator, flaw characteristics, etc. Therefore, a statistical approach was used to determine detection reliability. The examination of the seeded specimens was 
based on either detecting or not detecting known existing voids. Since only two outcomes from this examination are possible, POD can be described by a binomial distribution. The degree of confidence in the probability of detection is limited by the total number of seeded flaws. POD was determined using the following expression (ref. 25):

$$
1-G=\sum_{X=5}^{N} \frac{N !}{X !(N-X) !} P_{L}^{X}\left(1-P_{L}\right)^{N-X}
$$

where $P_{L}$ is the lower-bound probability of detection, $G$ is the confidence level, $N$ is the total number of flaws, and $S$ is the number of detected flaws. The optimized-probability method (ref. 25) was used to subdivide the thickness sensitivity data into small intervals and to plot reliability curves for each material sample. This method was chosen because the thickness sensitivity (void size) data were not uniformly distributed throughout the data range and the total number of voids in specific intervals was not the optimum (due to practical considerations and other factors that prevented full control of implanted void sizes).

\section{SEEDED SPECIMEN PREPARATION AND CHARACTERIZATION}

\section{Specimen Preparation}

Green test bars were prepared either from -100 mesh $\alpha$-SiC powder containing boron an carbonaceous resin binders, or from -100 mesh $\mathrm{Si}_{3} \mathrm{~N}_{4}$ powder containing yttria and silica sintering additives. A selected amount of either power composition was poured into a double-action tungsten-lined-die, and the powder was leveled. Then, a selected number of styrene divinyl benzene (SDB) microspheres of the same size $(528,321$, or $200 \mu \mathrm{m}$ in diam) were placed on the surface of the powder layer. Thereafter, more powder of the same composition was placed in the die, and the whole green layer was pressed at $120 \mathrm{MPa}$ to form a specimen. The specimen was removed from the die, and its surfaces were dusted (i.e., cleared of microdebris by inert gas jets).

When the seeding process involved seeding SDB microspheres of 115,80 , or $50 \mathrm{\mu m}$ diameter, the procedure was modified. First, an initial powder layer was pressed at $60 \mathrm{MPa}$. The surface of the layer was then dusted using a molsture-free aero duster in order to remove loose powder. Subsequently, approximately 20 SDB microspheres of the same size were positioned along the longitudinal axis of the top surface of the green compacted layer. The microspheres (later volds) were photographically recorded. Then, more powder of the same compostion was placed in the die, and the whole test bar compacted at $120 \mathrm{MPa}$ in order to form a specimen containing seeded internal defects at known positions. Finally, the specimen was removed from the die, and its surfaces were dusted.

Final compaction of the green specimen was accomplished by vacuum sealing the seeded test bar in thin wall latex tubing and cold isopressing it at $420 \mathrm{MPa}$. After compaction, the seeded specimens were heated under vacuum to approximately $550^{\circ} \mathrm{C}$ ( 45 to $60 \mathrm{~min}$ hold at maximum temperature) to decompose the SOB microspheres. The dimensions of the samples were measured, and their densities were calculated. 
All green silicon nitride (GSN) test bars were sintered at $2140{ }^{\circ} \mathrm{C}$ for $2 \mathrm{hr}$ under a static nitrogen pressure of $5 \mathrm{MPa}$. The green silicon carbide (GSC) specimens were sintered at $2200^{\circ} \mathrm{C}$ for $30 \mathrm{~min}$ under an argon pressure of $0.1 \mathrm{MPa}$. The dimensions of the sintered test bars were measured and their densities were computed. After radiography of the specimens was performed, the specimens were diamond ground in order to remove material from the specimen surface until the voids were exposed. The voids were then characterized using optical and electron microscopy respectively.

\section{Void Characteristics}

During the decomposition of the microsphere seeds, some of the powder which had been in contact with the microspheres was drawn into the resulting cavities (fig. 2). Typical internal void morphology in the green state is shown in figure 3. In general, the cavity was elliptical in shape with its minor axis along the die compression direction, and it was partially filled with powder. There was no indication that the decompositions of the SDB microspheres introduced any other defects or residue.

After sintering, the volume of the resulting cavity in sintered silicon nitride (SSN) and in sintered silicon carbide (SSC) was reduced due to an overall shrinkage. The resulting cavity surfaces in SSC were smooth. Figure 4 shows a typical void in SSC after being exposed to the surface via polishing. The resulting cavities in SSN exhibited two different morphologies. One morphology (type A) consisted of clusters of grains projecting from the original cavity walls as shown in figure 5. The other morphology (type B) consisted of an yttrium-rich shell as shown in figure 6 . Figures $5(a)$ and $6($ a) show typical void morphologies after being exposed to surface via polishing the SSN specimens. Figure $6(b)$ highlights the relative difference in average atomic number between the void region and the rest of the specimen. The formation of a yttrium rich shell is well contrasted in backscattered-electron photomicrographs shown in figure 7. A typical energy dispersive spectrum collected at a region free from seeded internal voids in a SSN sample is shown in figure $8(a)$. Figure $8(b)$ displays the energy dispersive spectrum collected at an exposed type A void. The energy dispersive spectrum collected at an exposed type $B$ void shows relatively high peak of yttrium as shown in figure $8(c)$. Yttrium concentration is evident in type $B$ voids, whereas, in type $A$ and at a region free of seeded internal voids yttrium concentration hardly reflects the original yttrium content of the $\mathrm{Si}_{3} \mathrm{~N}_{4}$ composition. It should be noted that type $A$ voids are similar to naturally occuring voids that cause fracture in SSN bars of the same composition.

\section{Specimen Characteristics}

The seeded test bars that were prepared for this study had the same densities and compositions as typical green and sintered $\mathrm{Si}_{3} \mathrm{~N}_{4}$ (ref. 5) and SiC (ref. 26). The average green density for $\mathrm{Si}_{3} \mathrm{~N}_{4}$ was about 58 to 60 percent of the calculated theoretical density for the composition used. The average green density for SiC was about 64 percent of the calculated theoretical density. After sintering, the average sintered density for SiC varied from 94 to 97 percent of the theoretical density, while for $\mathrm{Si}_{3} \mathrm{~N}_{4}$ it was greater than 98 percent of theoretical. 


\section{EXPERIMENTAL}

\section{Microfocus Radiography}

Film radiography was the technique adopted in this research. The microfocus system was operated in the projection mode, and in the 30- to 60-kV range with a beam current range of 0.25 to $0.32 \mathrm{~mA}$. The system had a molybdenum anode (low $x$-ray photon energy 17 to $20 \mathrm{keV}$ ) and a $10 \mu \mathrm{m}$ focal spot (good geometric resolution capability). Test bars were positioned between the source and the film detector in order to produce an $x$-ray image with a magnification factor of 2.5 with an overall source-to-f $11 \mathrm{~m}$ distance equal to $30 \mathrm{~cm}$. The exposure time was varied from 5 to $20 \mathrm{~min}$.

All radiographs were manually developed. To obtain uniform results, extra care was taken to eliminate $\mathrm{f} 1 \mathrm{~lm}$ artifacts, maintain chemical concentrations, control solution tempeatures and processing times, and prevent over- or underexposure by densitometric control. Radiographs were examined with the aid of a $X 7$ measuring magnifier under variable intensity backlighting ( 1000 to $90001 \mathrm{~m} / \mathrm{m}^{2}$ ) and in subdued room lighting. Typical microfocus radiographs of SSN bars with seeded internal voids are shown in figure 9 .

\section{Data Reduction}

For green specimens the gathering and analysis of data on void detectability were performed by one person who had prior knowledge of the numbers, sizes, and locations of the seeded voids. Internal voids in green specimens could not be optically characterized because the green specimens had to be kept intact so that they could be sintered for further evaluation. Therefore thickness sensitivity data for green specimens were estimates based on the original diameters of the seeded SDB microspheres.

Following radiography of sintered specimens and compilation of void data, the internal volds were exposed by carefully grinding away material. The dimensions of the voids measured by optical microscopy appear in table $I$. Thickness sensitivity data were computed from the actual dimension of the void along the $x$-ray path direction. The error in the measurement of this dimension was estimated to be +10 percent of the reported value because of difficulties in grinding away the material enclosing the void.

The distribution of internal voids (seeded and detected) over the thickness sensitivity data for $\mathrm{SiC}$ and $\mathrm{Si}_{3} \mathrm{~N}_{4}$ bars is shown in figure 10 . These plots illustrate that (1) the thickness sensitivity data were not uniformly distributed thrughout the data range, and (2) the number of voids in specific intervals was limited. For these reasons the optimized-probability method (ref. 25) was used to subdivide the thickness sensitivity data into sma11 intervals and to plot reliablitty curves for each of the materials under consideration (figs. 12 to 13 ).

The plotted values of the POD $P_{L}$ are biased away from smaller, harderto-detect voids because in figures 12 and 13 each curve corresponds to the largest void size contained in the interval for which it was calculated. This conservative aspect of $P_{L}$ is countered by the fact that the location of the voids was known apriori, whereas in a normal inspection the location of the voids is not known. 
All POD curves were generated at a confidence level of 95 percent. This means that there is a 5 percent probability that the POD reported herein is an overestimate of the true probability of detection.

\section{RESULTS}

We found that our ceramic specimen preparation technique successfully duplicated test bars with properties identical to those of typical Sic and $\mathrm{Si}_{3} \mathrm{~N}_{4}$ materials (i.e., same density, composition, surface roughness, etc.). The dimensions of the seeded volds are summarized in table I. Our seeding process produced internal voids with relatively uniform sizes. In general, the seeded internal voids were identical to typical naturally occuring voids.

POD curves of microfocus radiography for surface voids (ref. 7) and for internal voids (present work) in GSC and GSN bars are compared in figure 12. The thickness sensitivity at the $90 / 95 \mathrm{POD} / \mathrm{CL}$ (probability of detection/ confidence leve1) is 2.4 and 2.6 percent for internal voids in GSN and GSC, respectively (table II). The thickness sensitivity at the $90 / 95 \mathrm{POD} / \mathrm{CL}$ is 1.7 and 1.4 percent for surface voids in GSN and GSC, respectively.

Figure 13 compares the POD curves for surface voids (ref. 9) and internal voids (present work) in SSC and SSN. The thickness sensitivity at the 90/95 $\mathrm{POO} / \mathrm{CL}$ is 1.5 percent for surface voids in both SSC and SSN. For the case of internal voids in $S S N$, the thickness sensitivity at the $90 / 95 \mathrm{POD} / \mathrm{CL}$ is 0.6 percent. In the case of internal voids in SSC two different POD curves were generated (fig. 13(b)). The POD curve labeled SSC3 was generated from the data gathered from specimens seeded with SDB microspheres with original diameters ranging from 80 to $528 \mu \mathrm{m}$. The POD curve labeled SSC1 was generated from the data gathered from specimens seeded with SDB microspheres with $50 \mu \mathrm{m}$ original diameter size only. The thickness sensitivity at the $90 / 95 \mathrm{POD} / \mathrm{CL}$ are 1.5 and 1.6 for SSC 3 and SSC1 respectively.

\section{DISCUSSION}

\section{Void Characterization Problems}

The resulting voids in GSC and GSN were elliptical in shape and partially filled with powder. Further, the void depth dimension and the amount of powder filling the resulting cavities can change from one specimen to another and even from one void to another. Hence, by not being able to fully characterize these voids, the POD curves shown in figure $12(a)$ are overly conservative, because thickness sensitivity was computed based on the original diameters of the seeded SDB microspheres and not on the actual dimension of the void along the $x$-ray beam direction.

We noted that the voids in SSN exhibited two distinct morphologies: type $A$ and type $B$. both types tended to enhance $x$-ray attenuation depending on the density, chemical composition, and thickness of the shell surrounding the cavity. The radiographic appearance of these voids varied from regions of lower density to regions of higher density in the surrounding matrix. Because of this, similar sized voids ranged from hard-to-detect to easy-to-detect, which directly affects the POD data. Figure $9(a)$ shows voids which appear as high density shells (dark regions on the black and wite print) surrounding 
low density regions (light regions on the black and white print). This holds true for the appearance of the voids in the right half of figure $9(b)$. Whereas, the voids in the left half of figure $9(b)$ and those in figure $9(c)$ appear as they should, i.e., as low density regions (light spots on the black and white print). The mechanism governing the shell formation in the immediate vicinity of the cavity is unknown.

\section{Void Detection Reliability}

The dimensions of the seeded voids in this study were selected to span a range of sizes considered critical in sintered structural ceramics. A key factor in our approach was to have unambiguous foreknowledge of the actual size and location of each void. This was essential to establishing POD statistics for volds in the silicon carbide and silicon nitride bars.

Thickness sensitivity rather than specific void diameter was selected as the basis of the POD statistics for two practical reasons: (1) void detectability depends primarily on image contrast sensitivity and secondarily on image spatial resolution; and (2) void detectability is a function of variations in the material thickness. In the test samples studied and in potential ceramic components, these thickness variations can significantly affect image contrast for a given flaw size. In addition, bulk density variations introduced during specimen processing will affect the image contrast of voids. Density variations within the test bars undoubtedly influenced the detectability of individual voids and, hence, the POD statistics presented herein.

The POD curves for internal voids in GSC and GSN indicate detection reliability of microfocus for voids that are partially filled with powder, this is typical to green ceramics. Since these voids could not be fully characterized detection reliability of microfocus for clean voids in green ceramics would have to be inferred from the POO curves for surface voids (figs. 12(b) and $(c))$ in the same material.

The POD curve for internal voids in SSN 1 llustrates an improvement in void detectability over that for surface voids in the same material (fig. 13(a)). This was because some internal voids appeared to have higher density than the surrounding matrix. This enhanced the image contrast, and reduced the degree of confusion relative to naturally occuring voids. Apparently local density/ chemical variations will affect the image contrast of voids. This is true especially for materials where additives of high atomic numbers are used to promote the sintering process.

The POD curve for internal volds in SSC3 illustrates slight improvement in void detectability over internal voids in SSCl (fig. 13(b)). This improvement in void detectability reflects the effect of the dimensions of the voids on the $x$-ray detectability, i.e., the dimensions of the voids in SSCI are approaching values which limit the image contrast capability. The POD curve for internal voids in SSC3 and that for surface voids in SSC (fig. 13(b)) yielded identical results over the thickness sensitivity range between 1.3 and 2.3 percent. This implies that, detection reliablitity of microfocus for internal voids can be.inferred from POD curves of surface voids in materials if local density/chemical variations are not present. 
The results reported herein were obtained for specimens 2 to $7 \mathrm{~mm}$ thick. Since data was obtained only for specially-prepared specimens in this thickness range, POD given herein can be taken to. apply only for ceramic material of similar thickness and composition. It is not valid to adopt these POD curves for similar materials which have larger thicknesses and/or smaller voids than those reported herein. For a given void size, larger thicknesses mean the presence of increased density variations within the sample and the presence of increased scattered radiations which directly affect the image contrast. Also for a given thickness the presence of smaller voids would reduce the image contrast (see eq. 6). This was demonstrated in the POD curves of SSC1 and SSC3.

\section{CONCLUSION}

Projection microfocus radiography is a viable technique for detecting internal voids in monolithic structural ceramics, e.g., SiC and $\mathrm{Si}_{3} \mathrm{~N}_{4}$. Probability of detection statistics for critical size voids in these materials were established by the study described herein. These statistics were based on specially-prepared modulus-of-rupture type bars. The bars were systematically seeded with a range of vold sizes that permited evaluation of the limits of detection sensitivity of the projection microfocus technique. It was found that microfocus radiographic sensitivity at $90 / 95$ probability of detection/ confidence level is:

(1) Between 2.4 and 2.6 percent of thickness for internal voids that are partially filled with powder (as is commonly the case) in green $\mathrm{SiC}$ and $\mathrm{Si}_{3} \mathrm{~N}_{4}$.

(2) Between 1.5 and 1.6 percent of thickness for internal and surface voids in sintered SiC. $\mathrm{Si}_{3} \mathrm{~N}_{4}$.

(3) Better than 1.5 percent of thickness for internal voids in sintered

It was also shown that the detection reliability of microfocus radiography for internal voids can be inferred from probability of detection curves of surface voids in the same material if local density/chemical variations are not present.

\section{REFERENCES}

1. J.E. Harper, ARPA/NAVAIR Ceramic Gas Turbine Engine Demonstration Program, pp. 645-664, in Ceramics for High-Performance Applications III: Reliability, Plenum Press, New York, 1983.

2. R.B. Shulz, Overview of U.S. Department of Energy Ceramic Gas Turbine Program, pp. 21-28, Ceramics for High Performance Applications III: Reliability, Plenum Press, New York, 1983.

3. A.G. Evans, Aspects of the Reliability of Ceramics, pp. 63-80, in Defect Properties and Processing of High Technology Nonmetalif Materials, North Holland, New York, 1984.

4. W.B. Hall, and R.L. Nichols, Reliability of Structural Brittle Materials, in Research Reports: 1984 NASA/ASEE Summer Faculty Fellowship Program, NASA CR-171317, (1985). 
5. D.M. Mleskowski, W.A. Sanders, and L.A. Pierce, Reliability of Two Sintered Silicon Nitride Materials, NASA TM-87092, (1985).

6. A.G. Evans, G.S. Kino, B.T. Khuri-Yakub, and B.R. Tittman, Mater. Eval., $\underline{35}(4), 85,(1977)$.

7. A.P.S. Teotia, and L.R. Johnson, Structural Ceramics in Transportation: Fue 1 Implications and Economic Impacts, CONF-850115-4, (1985).

8. S.J. Klima, NDE for Heat Engine Ceamics, NASA TM-86949, (1984).

9. G.Y. Baaklini, J.D. Kiser, and D.J. Roth, Radiographic Detectability Limits for Seeded Voids in Sintered Silicon Carbide and Silicon Nitride, NASA TM-86945, (1984).

10. D.J. Roth, S.J. Klima, J.D. Kiser, and G.Y. Baaklini, Reliablilty of Void Detection in Structural Ceramics Using Scanning Laser Acoustic Microscopy, NASA TM-87035, (1985).

11. D.S. Kupperman, H.B. Karplus, R.B. Poeppe1, W.A. Ellingson, H. Burger, C. Robbins, and E. Fuller, Application of NDE Methods to Green Ceramics: Initial Results, ANL/FE-83-25, Argonne National Laboratory, (1984).

12. R.A. Roberts, W.A. Ellingson, and M.W. Vannter, A Comparison of X-ray Computed Tomography, Through Transmission Ultrasound, and Low-kV X-ray Imaging for Characterizing Gren-State Ceramics. Proceedings of the 15th Symposium on Nondestructive Evaluation, to be published (1985).

13. P.K. Khandelwal, R.R. Kinnick, and P.W. Heitman, Am. Ceram. Soc. Bull., 64. 1112, (1985).

14. R.W. Rice, J.J. Mecholsky, S.W. Frieman, and S.M. Morey, Failure Causing Defects in Ceramics: What NDE Should Find, NRL-MR-4075, Naval Research Laboratory, (1979). (AD-A078234).

15. K. Nishida, Silicon Nitride, pp. 21-24, in The Development of Structural Fine Ceramics in Japan. The Japan Industrial and Technological Bulletin, Japan External Trade Organization, Tokyo, (1983).

16. R.W. Rice, S.W. Freiman, J.J. Mecholsky, Jr., R. Ruh, and Y. Harada, Fractography of $\mathrm{Si}_{3} \mathrm{~N}_{4}$ and $\mathrm{SiC}$, pp. 669-687, in Ceramics for High Performance Applications II, Edited by J.J. Burke, E.N. Lenoe, and R.N. Katz, (1977).

17. R.W. Rice, J. Mater. Sci., 19, 895 (1984).

18. R. Halmshaw, Industrial Radiology, Applied Science Publishers, London, 1982.

19. R. McMaster, Nondestructive Testing Handbook, vol. I, Chapters 13-27, Ronald Press Co., New York, 1959. 
20. R. Kooswsky, Defect Detection in Hot-Pressed Silicon Nitride, pp. 665-685, in Ceramics for High Performance Applications, edited by J.J. Burke, A.E. Gorum, and R.N. Katz, Brook Hill Publishing Co., Chestnut Hill, MA, 1974 .

21. D.W. Richerson, and K.M. Johansen, Ceramic Bas Turbine Engine Demonstration Program, REPT-21-4410, Garret Turbine Engine Co., (1982). (AD-A117088.)

22. R.W. Parish, High Resolution in the Aero Engine Industry, in Nondestructive Inspection Methods for Propuision Systems and Components, AGARD-LS-103, Advisory Group for Aerospace Research and Development, Nevilly-Sur-Seine, France, (1979). (AD-AD69901.)

23: R.L. Smith, The Effect of Scattering on Contrast in Microfocus Projection X-Radiography, Br. J. Non-Destr. Test., 22, 236 (1980).

24. Radiological Health Handbook, U.S. Department of Health, Education, and Welfare, pp. 137-140, 1970.

25. P.F. Packman, S.J. Klima, R.L. Davies, J. Malpani, J. Moyzis, W. Walker, B.G.W Yee, and D.P. Johanson, Reliability of Flaw Detection by Nondestructive Inspection, pp. 414-424, in Metals Handbook, vol. 11, 8th ed. Edited by H.E. Boyer, American Society for Metals, Metals Park, OH, 1976.

26. S. Dutta, J. Mater. Sc1., 19, 1307 (1984). 
TABLE I. - DIMENSIONAL CHARACTERISTICS OF RESULTING INTERNAL VOIOS IN SINTERED MATERIALS

\begin{tabular}{|c|c|c|c|c|c|c|c|}
\hline \multirow[t]{2}{*}{ Materials } & \multirow{2}{*}{$\begin{array}{l}\text { Specimen } \\
\text { thickness } \\
\text { range, } \\
\mathrm{mm}\end{array}$} & \multirow[t]{2}{*}{$\underset{\mu \mathrm{m}}{\text { Sphere diam, }}$} & \multirow{2}{*}{$\begin{array}{l}\text { Number of } \\
\text { spheres } \\
\text { seeded }\end{array}$} & \multicolumn{4}{|c|}{$\begin{array}{l}\text { Resulting Void Dimension } \\
\text { Void depth, } \mu \mathrm{m} \text { Void diameter, } \mu \mathrm{m}\end{array}$} \\
\hline & & & & Mean & $\begin{array}{l}\text { Standard } \\
\text { deviation }\end{array}$ & Mean & $\begin{array}{l}\text { Standard } \\
\text { deviation }\end{array}$ \\
\hline $\mathrm{Si}_{3} \mathrm{~N}_{4}$ & $2-7$ & $\begin{array}{r}80 \\
115 \\
200 \\
321 \\
528\end{array}$ & $\begin{array}{l}69 \\
39 \\
31 \\
28 \\
21\end{array}$ & $\begin{array}{r}20 \\
37 \\
133 \\
233 \\
307\end{array}$ & $\begin{array}{r}4 \\
5 \\
17 \\
16 \\
14\end{array}$ & $\begin{array}{r}25 \\
68 \\
139 \\
267 \\
386\end{array}$ & $\begin{array}{r}6 \\
5 \\
8 \\
18 \\
15\end{array}$ \\
\hline $\mathrm{SiC}$ & $2-7$ & $\begin{array}{r}50 \\
80 \\
115 \\
200 \\
321 \\
528\end{array}$ & $\begin{array}{l}50 \\
47 \\
68 \\
19 \\
39 \\
43\end{array}$ & $\begin{array}{r}32 \\
59 \\
77 \\
165 \\
297 \\
477\end{array}$ & $\begin{array}{r}3 \\
6 \\
10 \\
29 \\
19 \\
47\end{array}$ & $\begin{array}{r}58 \\
100 \\
131 \\
194 \\
307 \\
505\end{array}$ & $\begin{array}{r}3 \\
8 \\
8 \\
11 \\
15 \\
28\end{array}$ \\
\hline
\end{tabular}




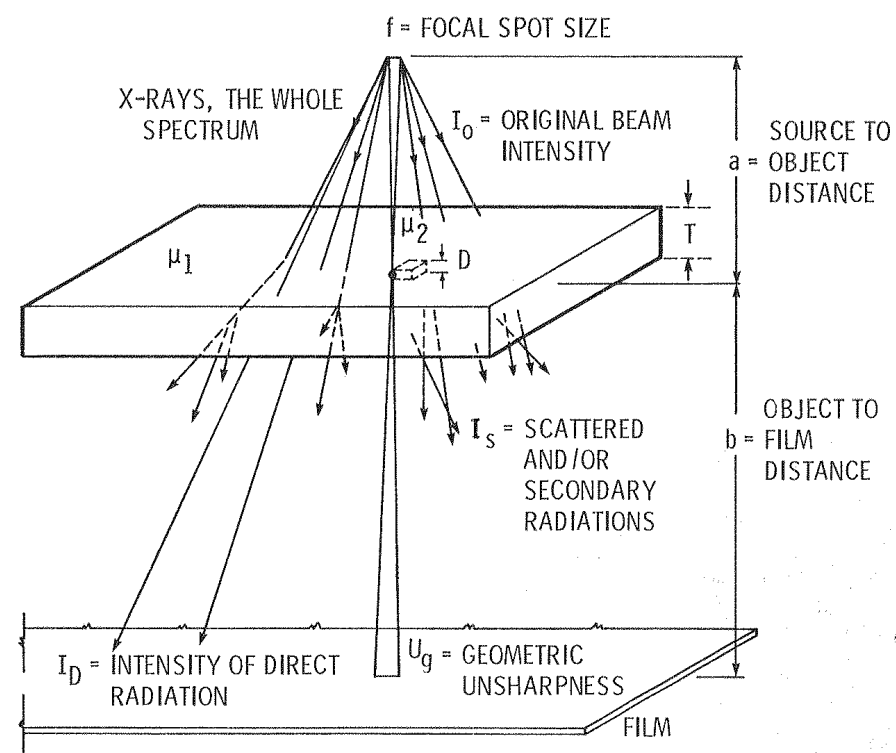

Fiqure 1. - A schematic configuration of microfocus projection radioaraphy where $D$ is thickness of defect, $T$ is thickness of sample, $\mu$ is attenuation coefficient of the matrix, and $\mu_{2}$ is attenuation coefficient of the defect.

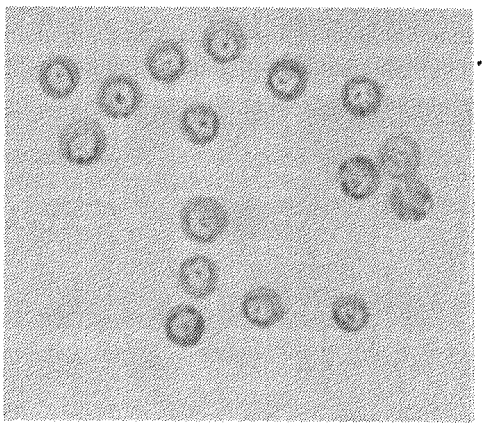

(a) In green isopressed $\mathrm{Si}_{3} \mathrm{~N}_{4}$.

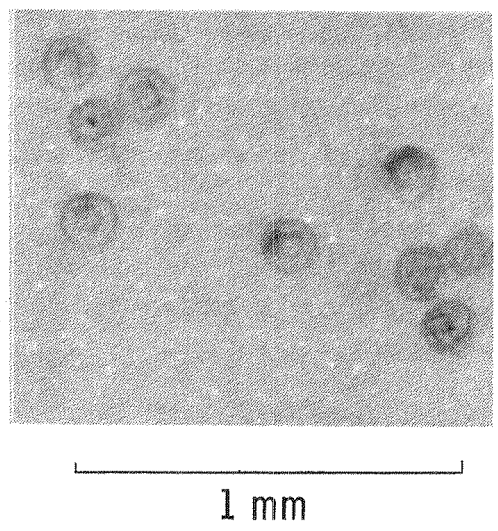

(b) In green isopressed SiC.

Figure 2. - Optical photographs of internal voids as exposed to surface after decomposition of SDB microspheres. 


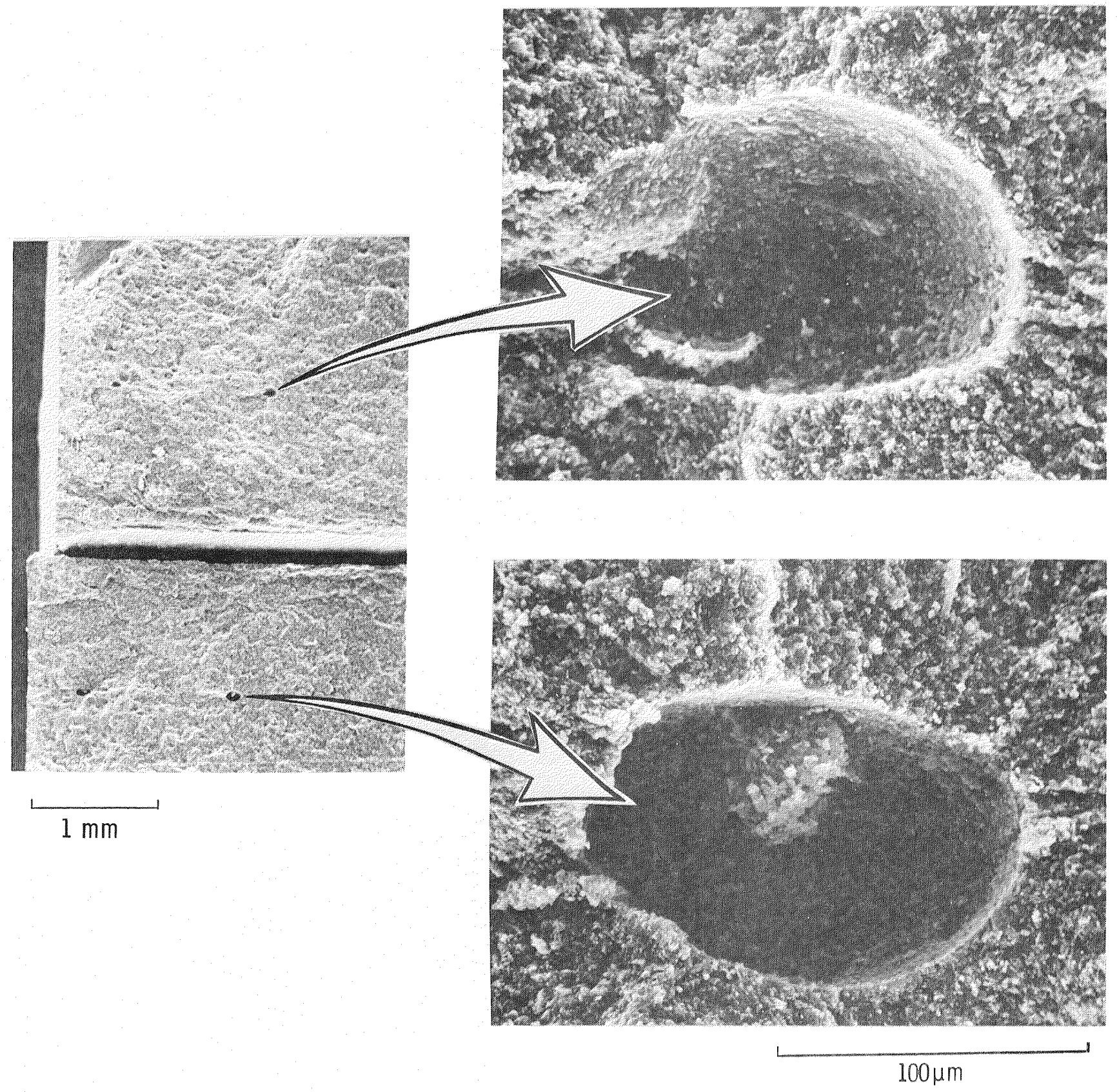

Figure 3. - Scanning electron fractographs of typical internal voids in green SiC bars. 


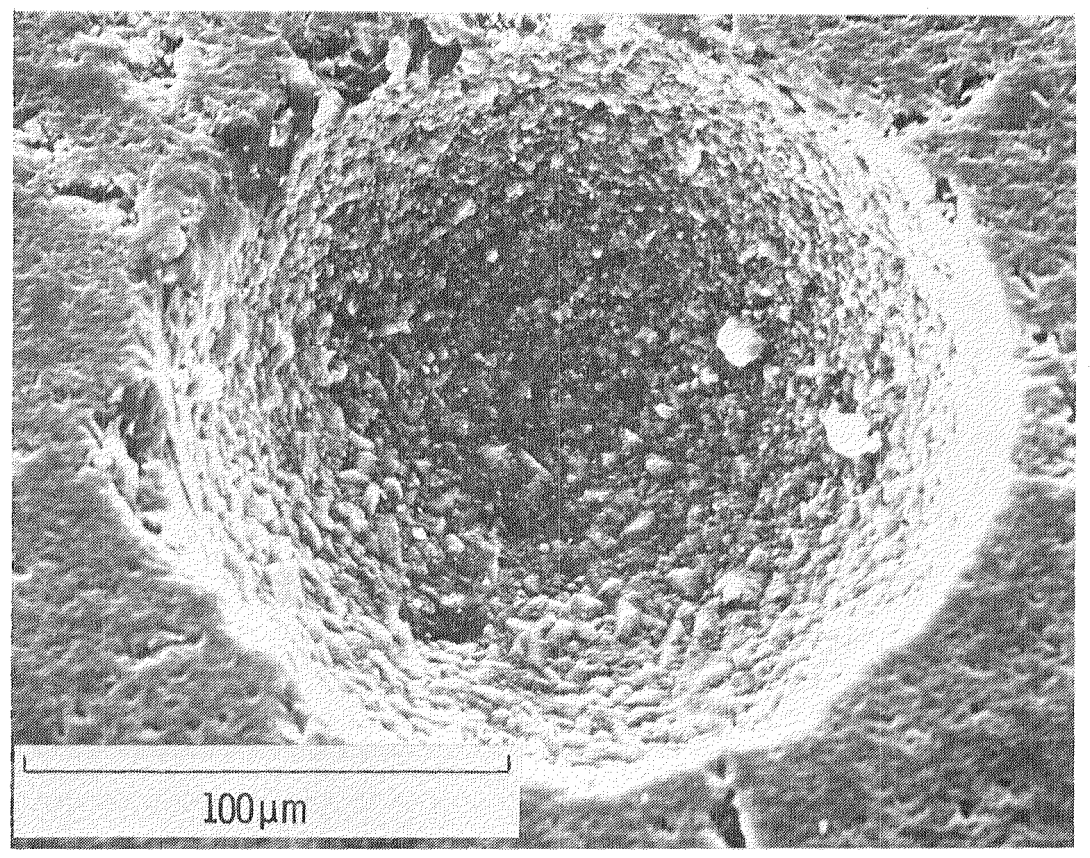

(a) As exposed to surface.

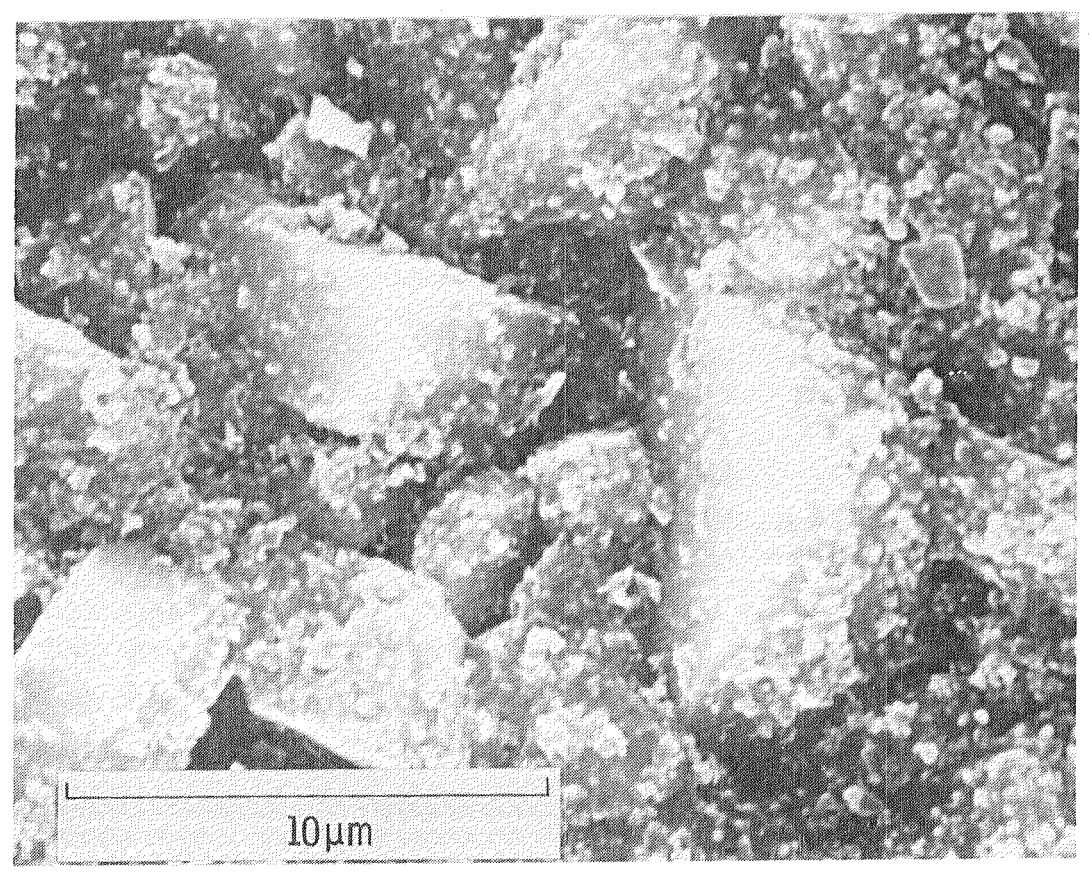

(b) texture of the cavity-wall--surface.

Figure 4. - Scanning electron micrographs of a typical void in sintered SiC bars. 


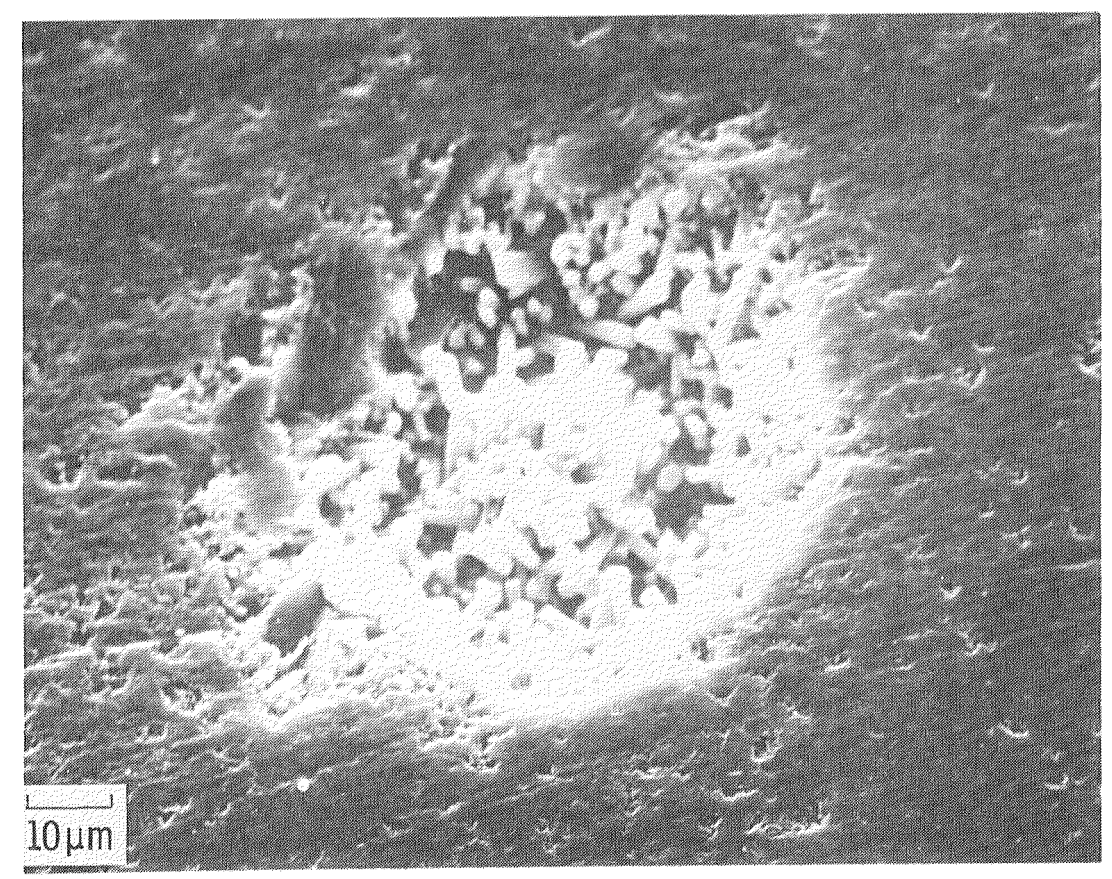

(a) As exposed to surface.

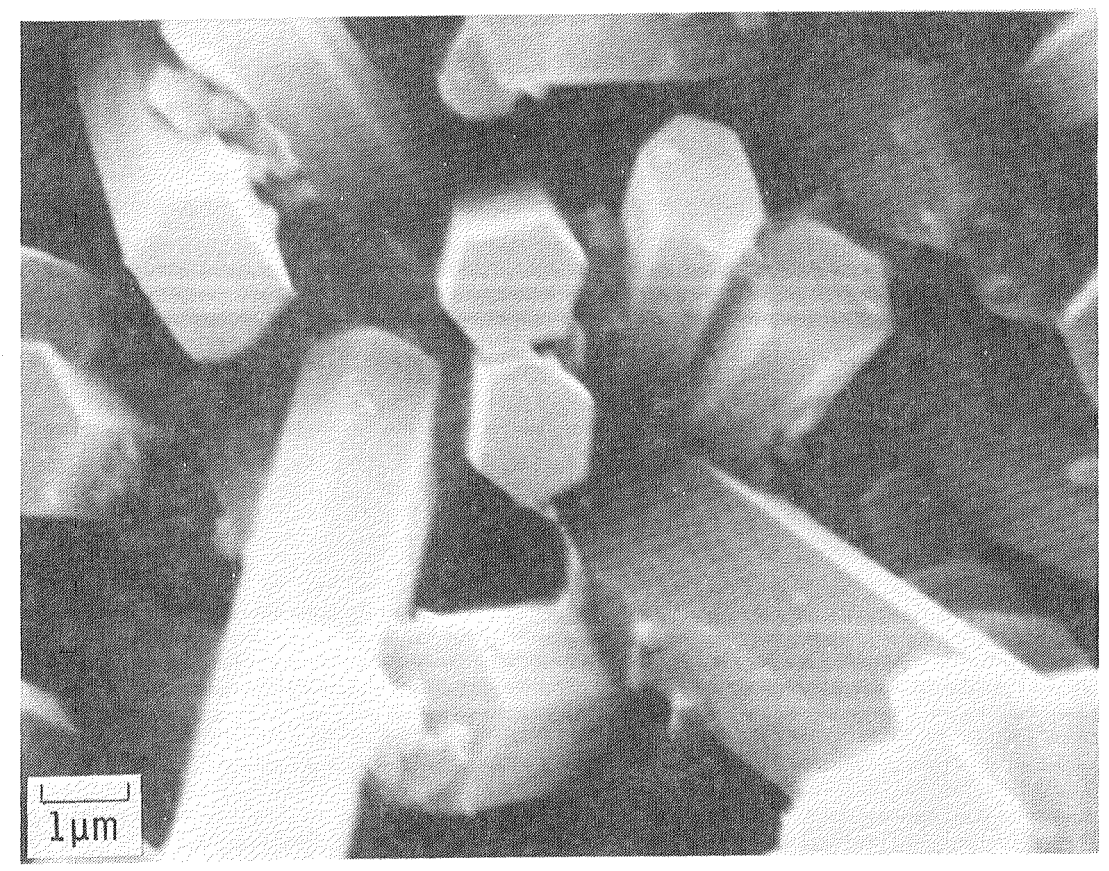

(b) Clusters of arains projecting from the cavity walls.

Figure 5. - Scanning electron micrographs of type A internal voids in sintered $\mathrm{Si}_{3} \mathrm{~N}_{4}$. 


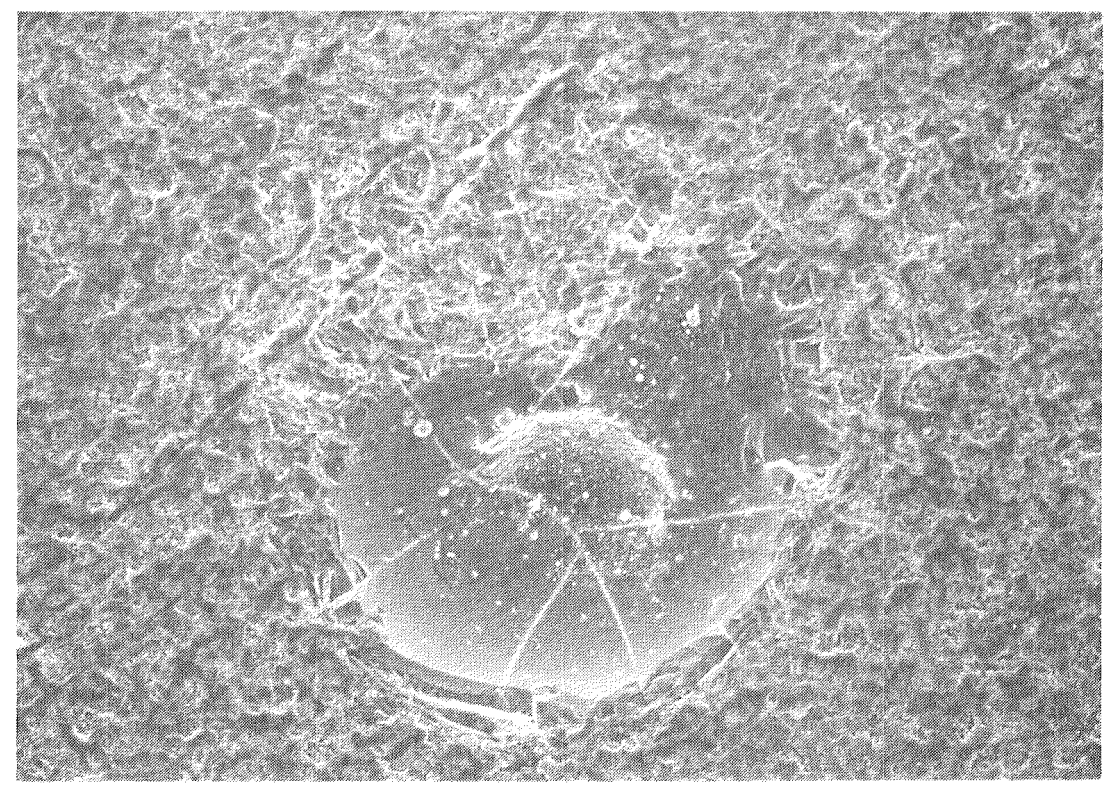

(a) As exposed to surface.

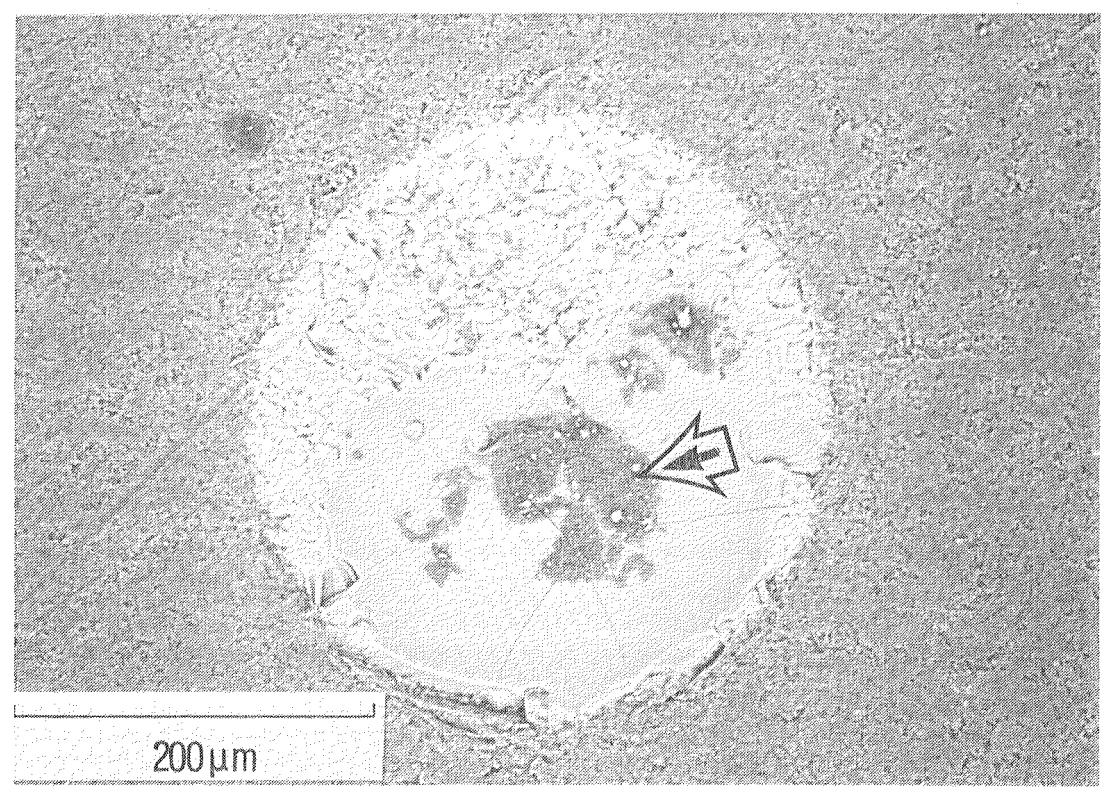

(b) Backscattered electron image of same region.

Figure 6. - Scanning electron micrographs of type B internal voids in sintered $\mathrm{Si}_{3} \mathrm{~N}_{4}$. Arrow indicates region to be shown at higher magnification in figure 7. Backscattered electron image (b) highlights yttrium rich region. 


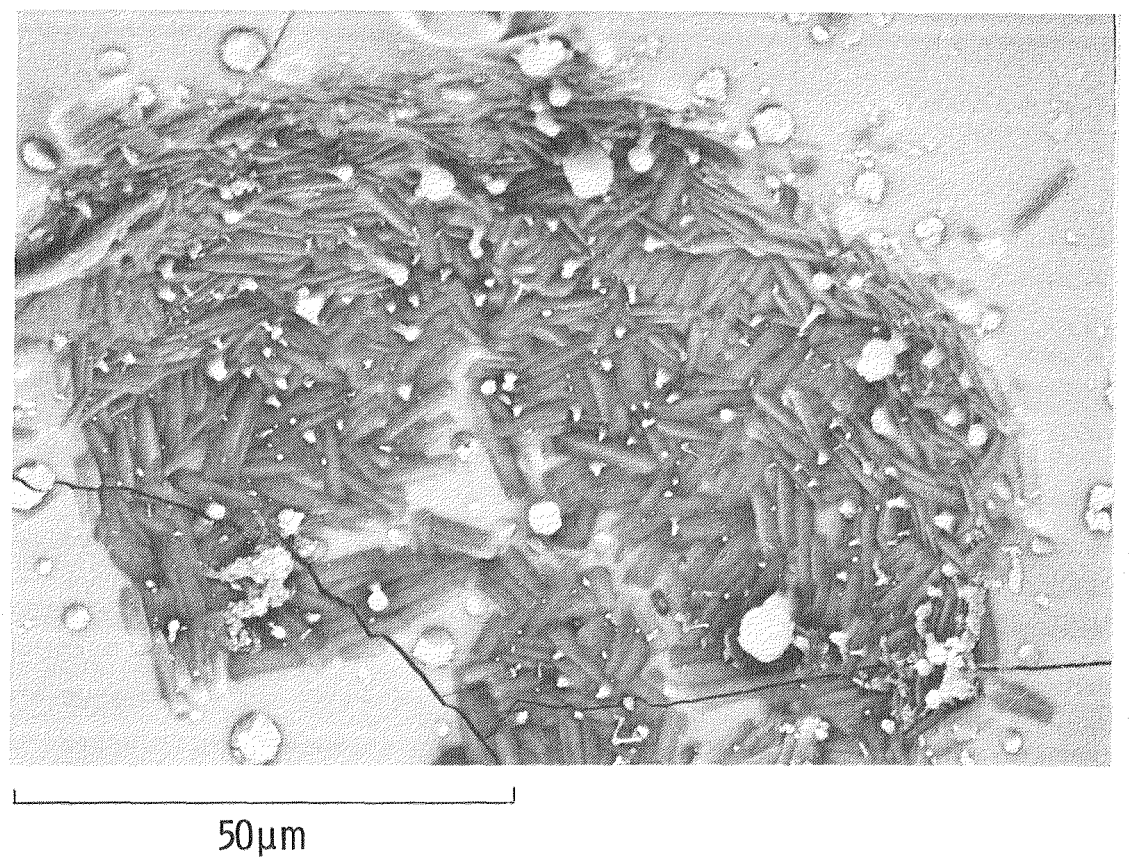

(a) Backsctattered electron image at moderate magnification.

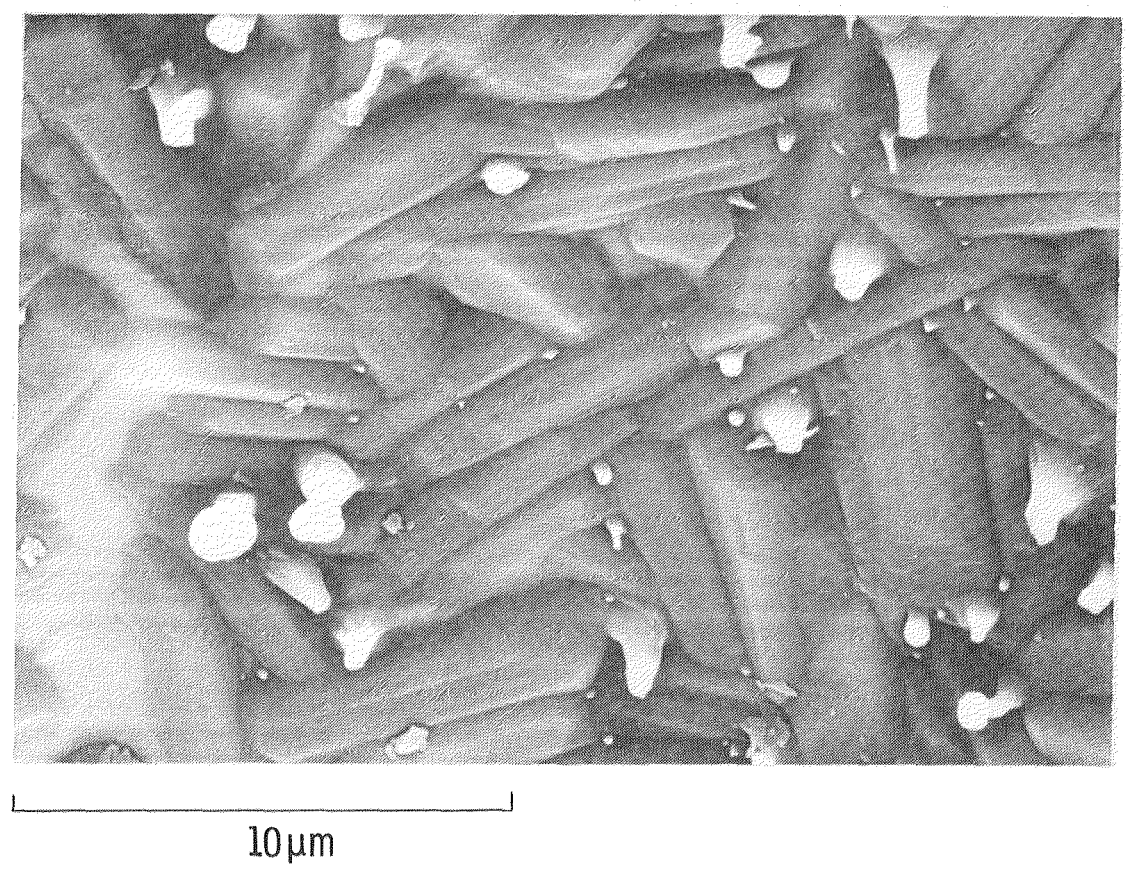

(b) Same image as (a) but contains fine scale information.

Figure 7. - Images of the dark region (as indicated by the arrow in figure 6 (b) ) illustrating the for mation of an yttrium rich shell. 


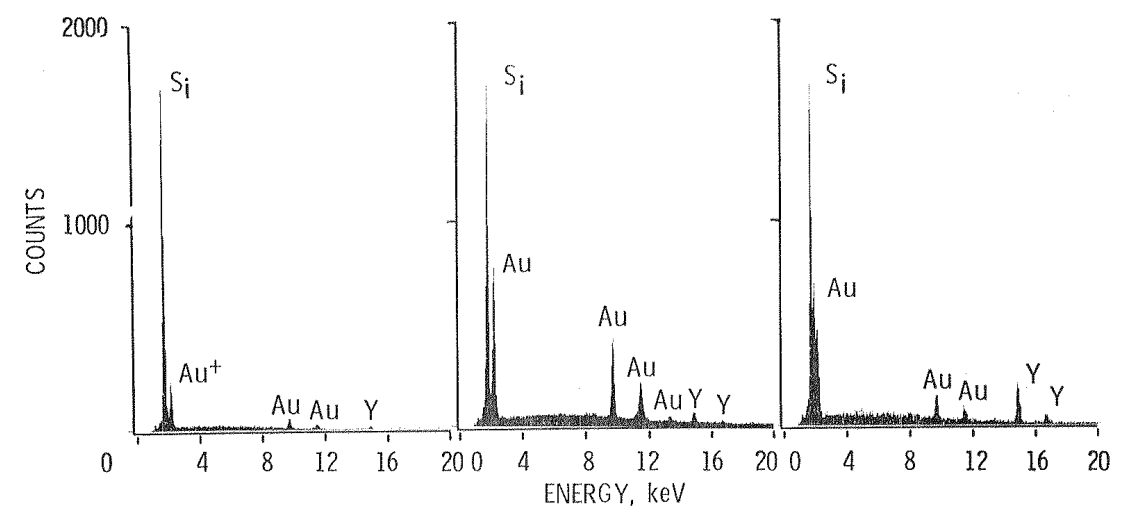
(a) Collected at a region free of seeded internal voids.
(b) Collected at a type $\mathrm{A}$ void.
(c) Collected at a type B void.

Figure 8. - Energy dispersive spectra illustrating the elemental constituents of selected regions in sintered $\mathrm{Si}_{3} \mathrm{~N}_{4}$ bars.

* Note: Yttrium concentration.

+ Gold coating necessary to image the ceramic bars.
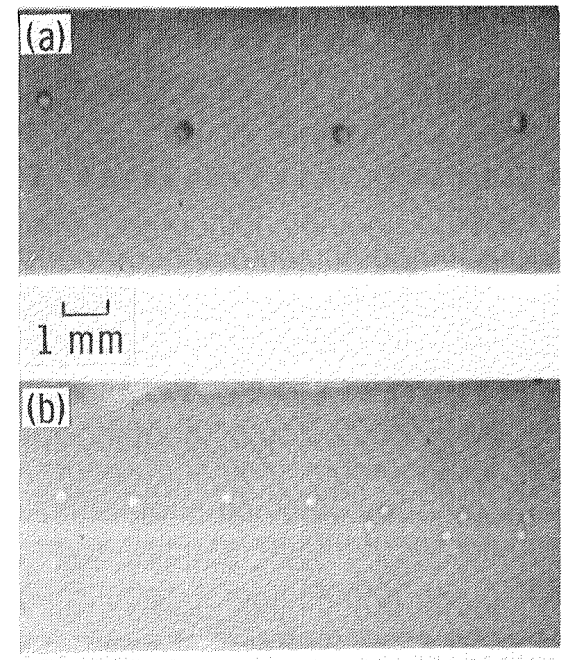

\section{$1 \mathrm{~mm}$}

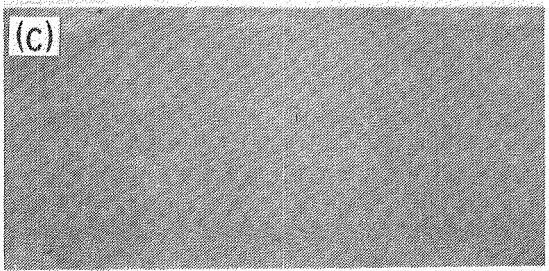

$1 \stackrel{1}{m m}$

Figure 9. - Microfocus radiographs of sintered $\mathrm{Si}_{3} \mathrm{~N}_{4}$ bars with seeded internal voids as a result of decomposition of SDB spheres. (a) $528 \mu \mathrm{m}$ in diameter, (b) $321 \mu \mathrm{m}$ in diameter, (c) $200 \mu \mathrm{m}$ in diameter。 


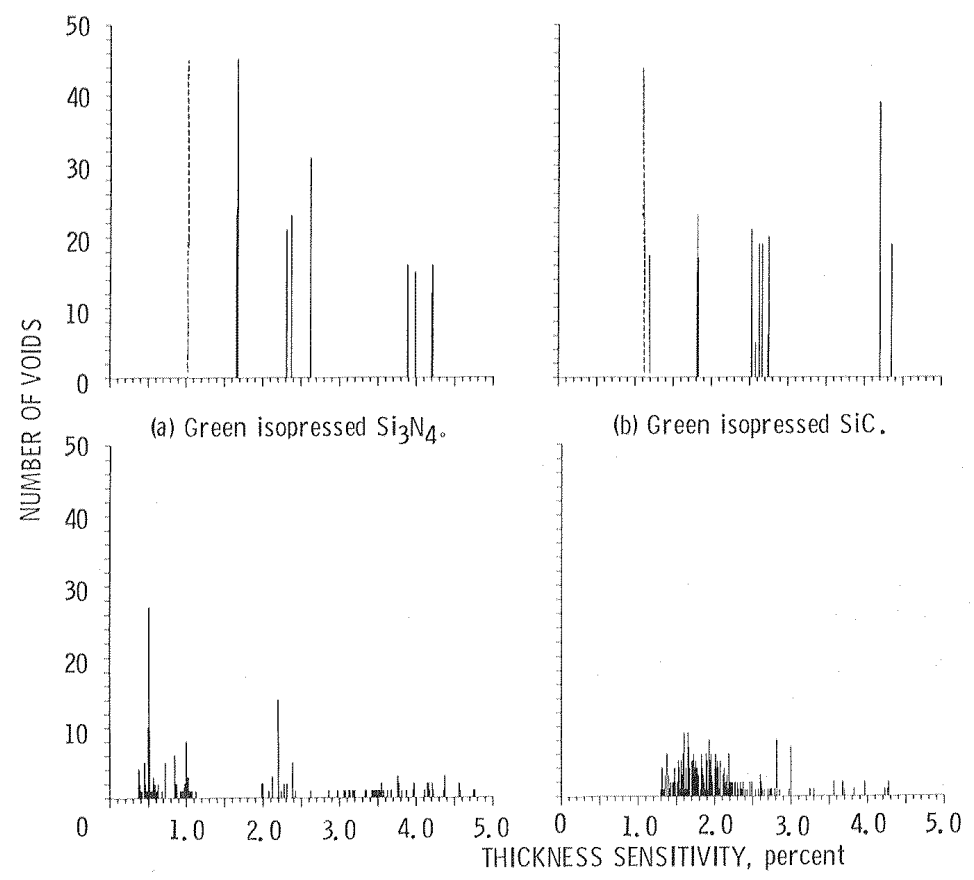

(c) Sintered $\mathrm{Si}_{3} \mathrm{~N}_{4}$.

(d) Sintered SiC (SSC3).

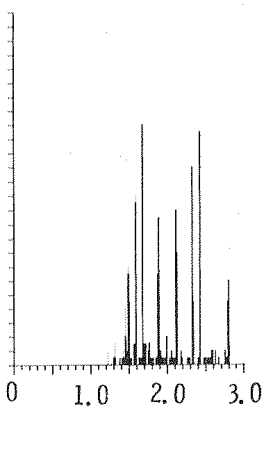

(e) Sintered SiC (SSCI).

Figure 10. - Distribution of internal voids (seeded and detected) in $\mathrm{Si}_{2} \mathrm{~N}_{A}$ and $\mathrm{SiC}$ bars. Thickness sensitivity $\%=100$ (void dimension in $x$-ray beam direction)/(thickness of specimen in same direction).

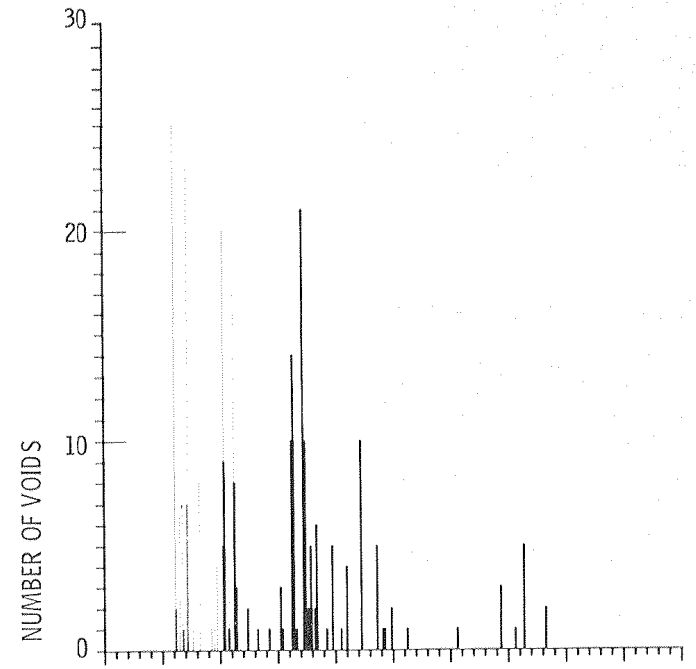

(a) Green isopressed $\mathrm{Si}_{3} \mathrm{~N}_{4}$.

20

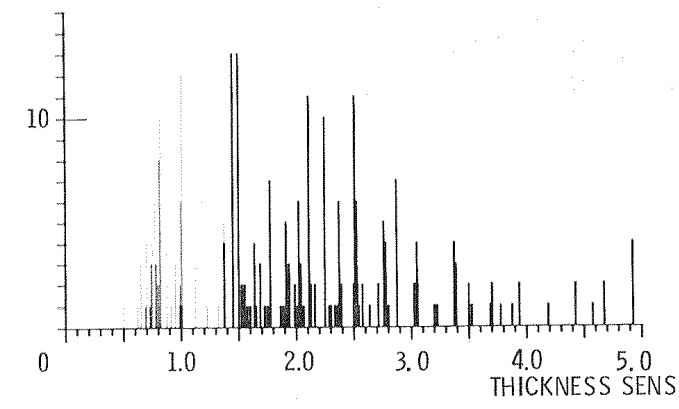

(c) Sintered $\mathrm{Si}_{3} \mathrm{~N}_{4}$.

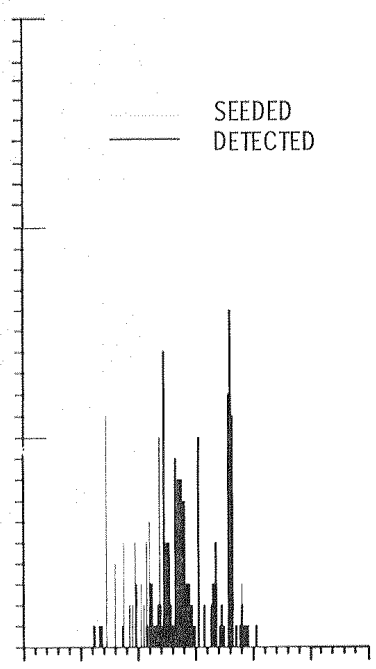

(b) Green isopressed SiC.

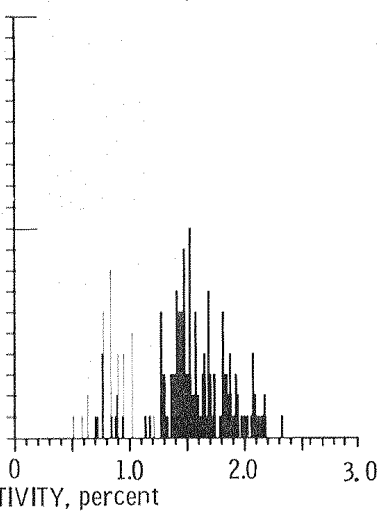

(d) Sintered SiC.

Figure 11. - Distribution of surface voids (seeded and detected) in $\mathrm{Si}_{2} \mathrm{~N}_{4}$ and $\mathrm{SiC}$ bars. Thickness sensitivity \% 100 (void dimension in $x$-ray beam direction)/(thickness of specimen in same direction). (Figure taken from ref. 9). 

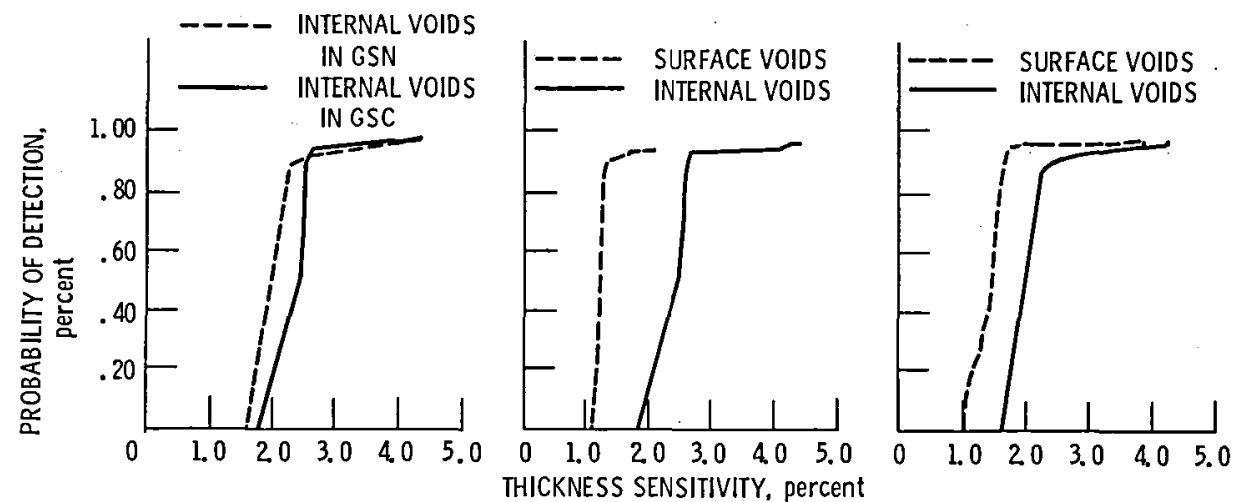

(a) Green $\mathrm{SiC}$ and $\mathrm{Si}_{3} \mathrm{~N}_{4}$.

(b) Green $\mathrm{SiC}$.

(c) Green $\mathrm{Si}_{3} \mathrm{~N}_{4}$.

Figure 12. - Lower bound probability of detection of surface (ref. 9) and internal voids in qreen isopressed $\mathrm{SiC}$ (GSC) and $\mathrm{Si}_{3} \mathrm{~N}_{4}$ (GSN) bars calculated at 95 percent confidence level. Thickness sensitivity $\%=100$ (void dimension in $\mathrm{x}$-ray beam direction)/(thickness of specimen in same direction).
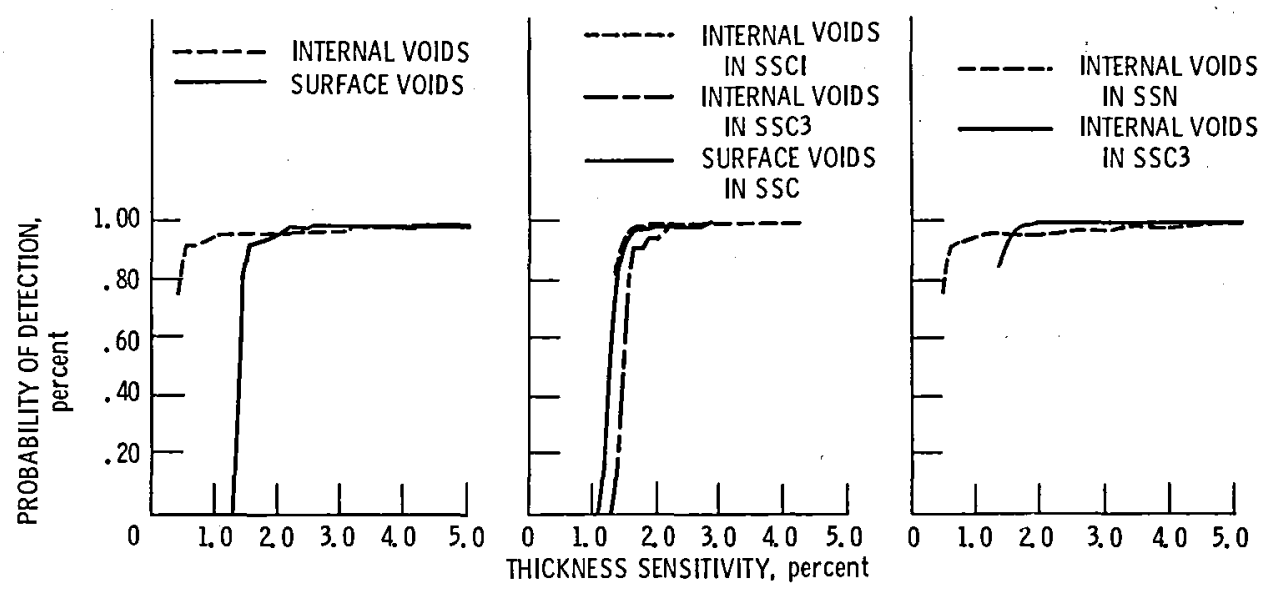

(a) Sintered $\mathrm{Si}_{3} \mathrm{~N}_{4}$.

(b) Sintered SiC.

(c) Sintered $\mathrm{SiC} \& \mathrm{Si}_{3} \mathrm{~N}_{4}$.

Figure 13. - Lower bound probability of detection of surface (ref. 9) and internal voids in sintered SiC (SSC) and $\mathrm{Si}_{3} \mathrm{~N}_{4}$ (SSN) bars calculated at 95 percent confidence level. Thickness sensitivity \% = 100 (void dimension in $\mathrm{x}$-ray beam direction)/(thickness of specimen in same direction). 


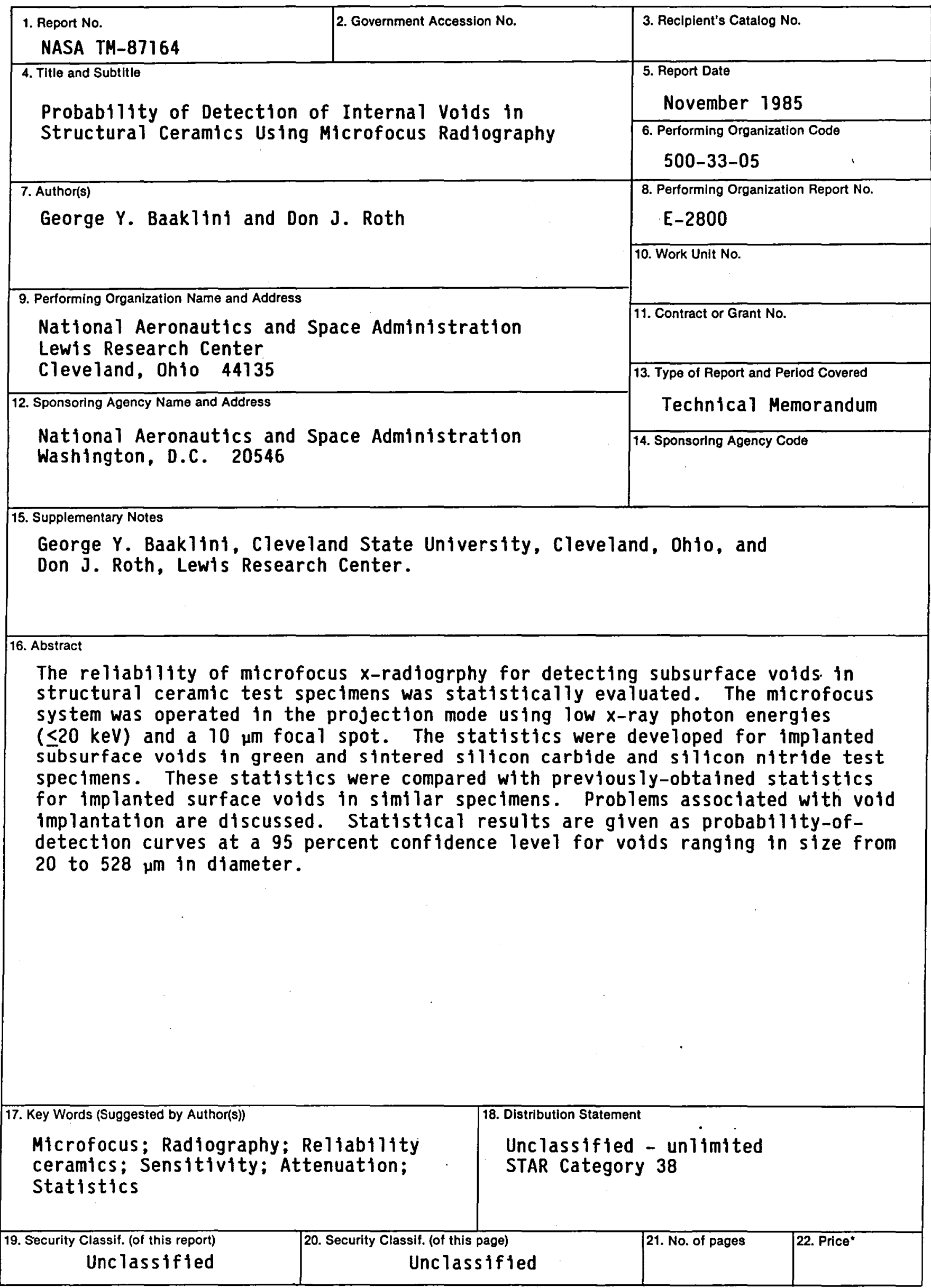

*For sale by the National Technical Information Service, Springfield, Virginia 22161 
End of Document 